\title{
Analysis of the influence of panel characteristics on odor measurement based on the air dilution olfactory method in Korea
}

\author{
Sun-Tae $\mathrm{Kim}^{{ }^{1}}$, Seokjun Lee ${ }^{2}$, Bongbeen Yim $^{3}$ \\ ${ }^{1}$ Department of Environmental Engineering, Daejeon University, Daejeon 34520, Republic of Korea \\ ${ }^{2}$ Air Works Inc., Daejeon 34520, Republic of Korea \\ ${ }^{3}$ Environmental R\&D Center, enbion Inc., Daejeon 34026, Republic of Korea
}

\begin{abstract}
This study was to objectify differences in the results of odor testing according to the characteristics of panel members that participate in air dilution olfactory method (ADOM) testing. When differences in the results of olfactory testing were reviewed in relation to characteristics of the panelists, the result of entire panels for the site boundary Proficiency Testing Materials (PTMs) showed no difference according to panelist sex, age, smoking status, and past participation in ADOM tests. As for the outlet PTMs, distinct differences appeared in relation to the smoking status and age of panelists. The frequency distribution for all the panelists $\left(\operatorname{Dev}\left(\mathrm{D} / \mathrm{T}_{\text {total }}\right)\right)$ showed a form similar to a normal distribution, so it is thought to be more appropriate for the review of effect of panelist characteristics on the result of air dilution olfactory tests. In addition, the ADOM testing method implemented as the standard method for odor compounds in $\operatorname{Korea}\left(\mathrm{Dev}\left(\mathrm{D} / \mathrm{T}_{3}\right)\right)$ will have to be implemented along with a concurrent assessment, for the purpose of identifying the effect of panelist characteristics on administrative dispositions against malodors.
\end{abstract}

Keywords: Odor, Olfactory sense, Olfactory test, Panelists, Proficiency testing materials

\section{Introduction}

There exist in nature, a number of offensive odors that can be described using diverse and unique characteristics of smell, as well as by the intensity, frequency, duration time, and pleasant or unpleasant feeling (hedonic tone) of the smell. Although some odor materials can identify using a chromatographic technique with a suitable detector, among these are a variety of substances that cannot be measured by chemical analysis or which cannot be clearly identified when they exist in mixture [1]. Generally, the instrumental analysis and air dilution olfactory methods are used for the assessment of offensive odors. The instrumental analysis method involves quantitatively analyzing odor substances that belong to the sulfur family, aldehyde family, ammonia, the amine family, and the VOC family of substances. The instrumental techniques such as an electronic nose system (sensor arrays) capable to measure odor substances (i.e., $\mathrm{NH}_{3}$ and $\mathrm{H}_{2} \mathrm{~S}$ ) and to qualitatively and quantitatively characterize a complex odor is now commercially available [2-4]. The air dilution olfactory method involves assessment of odors diluted to a threshold ratio through detection by the human olfactory sense [5].

Among the olfactory odor detection methods, olfactometry utilizing the human olfactory sense is the most effective and useful way of measuring odors. Olfactometry is advantageous in that it can detect diverse odor substances and that the existence of a bad odor can be measured under conditions similar to those in which residents in a community have been offended by a serious malodor problem. In addition, olfactometry is more economical than the instrumental analysis method, which requires expensive analysis equipment appropriate for different kinds of odors. Thus, the air dilution olfactory method (ADOM) is widely utilized as the method of choice for the assessment of complex odors [6, 7].

However, the olfactometric technologies have some disadvantages, which can be summarized as follows; (1) various factors influencing odor assessment by panel members, (2) training for ensure the objectivity of panel members and high costs,
This is an Open Access article distributed under the terms of the Creative Commons Attribution Non-Commercial License (http://creativecommons.org/licenses/by-nc/3.0/) which permits unrestricted non-commercial use, distribution, and reproduction in any medium, provided the original work is properly cited.
Received March 7, 2018 Accepted June 20, 2018

${ }^{\dagger}$ Corresponding author

Email: envsys@dju.kr

Tel: +82-42-280-2534

Copyright (C) 2019 Korean Society of Environmental Engineers 
(3) differences in odor assessment by sensory panel members, (4) underestimation of olfactory onerousness for the community [8]. In particular, the result of olfactometry is affected by the characteristics of the (human) panel participating in the testing, including their sex, age, health conditions, etc. [9-12]. Also, European Standard (EN 13725), which defines a method for the objective determination of the odor concentration of a gaseous sample using dynamic olfactometry with human assessors, clearly defines what parameters effect to the result of olfactometry [13].

The National Institute of Environmental Research of Korea examines the proficiency of certified odor measurement agencies in measurement of complex odors, in order to manage the quality of results from the $\mathrm{ADOM}$ and to guarantee its reliability. The institute also checks the characteristics of panels that participate in complex odor tests, but there has been no case of analysis and objectification of the characteristics of Korean panels, such as their sex, age, whether they smoke or not, and how many times they have participated in olfactory tests.

The aim of this study was to objectify differences in the results of odor testing according to the characteristics of panel members that participate in $\mathrm{ADOM}$ testing. The first step was analysis of the results of the ADOM tests implemented by certified odor measurement agencies that were tested for complex order measurement proficiency in 2015. Then, the characteristics of the members of the panels that took part in those $\mathrm{ADOM}$ tests (e.g., including sex, age, whether they smoke or not, how many times they had participated in $\mathrm{ADOM}$ tests in the past), were identified; in order to reinforce the objectivity of complex odor assessments, which is legally mandatory in Korea.

\section{Materials and Methods}

\subsection{Proficiency Testing Materials for the Air Dilution Olfactory Method}

In Korea, 22 substances among the diversity of odor substances are designated as offensive odor substances. Among these, the composite substances toluene $+\mathrm{m}$-xylene, and dimethyl sulfide (DMS) + dimethyl disulfide (DMDS), of which the substance concentration is relatively higher in comparison with the intensity of the odor were selected as the Proficiency Testing Materials (PTMs) of the odor at the site boundary and outlet of a source of malodor, respectively [14]. The criteria of the Malodor Prevention Act for malodor discharge at the site boundary and outlet of an industrial area were considered in the selection of the PTMs. The Malodor Prevention Act permits discharge of odor diluted to a maximum of 1:20 at a site boundary and to a maximum of 1:1000 at the outlet of an industrial area. The level of concentration for the site-boundary PTMs for this study was set at toluene $(50.3 \mathrm{mmol} / \mathrm{mol})+\mathrm{m}$-xylene $(6.44 \mathrm{mmol} / \mathrm{mol})$ as shown in Table 1. The concentration for the outlet PTMs was set at dimethyl sulfide $(12.4 \mathrm{mmol} / \mathrm{mol})+$ dimethyl disulfide $(12.3 \mathrm{mmol} / \mathrm{mol})$. Those PTMs were manufactured and analyzed by the company RIGAS (Korea) according to ISO 6142:2001 [15] and ISO 6143:2001 [16]. The PTMs used for this study were injected into aluminum cylinders at $10 \mathrm{MPa}$ (at $20^{\circ} \mathrm{C}$ ) with nitrogen gas used as the balance gas. The mean dilution factor for the site-boundary and outlet PTMs were approximately $61 \mathrm{OU} / \mathrm{m}^{3}$ (relative standard deviation $=6.4 \%$, $\mathrm{n}=9$ ) and $5,100 \mathrm{OU} / \mathrm{m}^{3}$ (relative standard deviation $=4.4 \%$, $\mathrm{n}=30$ ), respectively.

For the delivery of PTMs to certified odor measurement agencies, materials manufactured to the same concentration are divided into small cylinders, or different materials are supplied at the same time from one cylinder, using a manifold. However, even if small cylinders of the same type are used, it is difficult to guarantee the homogeneity of the materials put into different cylinders. Differences between them may be caused when a manifold is used, because of possible differences in the conditions of material collection, for example in the rate of flow. Therefore, multiple processes for the verification of the homogeneity among sample materials are necessary. In order to distribute the site boundary and outlet PTM samples for air dilution olfactory tests for complex odors to certified odor measurement agencies, while maintaining the homogeneity between them, a large-volume Teflon bag (KIST, Korea) with $1.15 \mathrm{~m}^{3}(1.15 \times 1.15 \times 1.15$ $\mathrm{m})$ was manufactured. Before the first use of the bag, odorless air was injected and then it was tested for air leakage 24 hours later, to confirm its air-tightness. The Teflon bag was flushed three times using nitrogen gas (99.999\%) and then the PTMs for complex odor olfactory tests were injected. For three repeated analyses of the materials by one agency, $20 \mathrm{~L}$ of the site boundary PTMs and $10 \mathrm{~L}$ of the outlet PTMs were offered in polyester aluminum bags (Top Trading ENG, Korea). The complex odor olfactory tests were carried out within $48 \mathrm{~h}$ of delivery of the PTMs. Tests for the verification of the homogeneity and stability of the site boundary and outlet PTMs were also carried out. For the homogeneity testing, three groups of panelists (15 in each group) who had passed a panel screening test engaged in three repeated air dilution olfactory tests for the site boundary and outlet PTMs. For the stability testing, one group of panelists (five in the group) engaged in three air dilution olfactory tests for the site boundary and outlet PTMs for $72 \mathrm{~h}(24 \mathrm{~h}, 48 \mathrm{~h}$, and $72 \mathrm{~h}$ ).

Table 1. The Concentration for the Site Boundary and Outlet PTMs

\begin{tabular}{cccc}
\hline PTMs (Proficiency Testing Materials) as a complex odor & Concentration ( $\boldsymbol{\mu m o l} / \mathbf{m o l})$ & $U_{\text {rel }}$ (Relative expanded uncertainty) (\%) \\
\hline \multirow{2}{*}{ Site boundary } & Toluene & 50.3 & \pm 3 \\
& m-Xylene & 6.44 & \pm 5 \\
\hline \multirow{2}{*}{ Odor outlets } & Dimethyl sulfide & 12.4 & \pm 5 \\
& Dimethyl disulfide & 12.3 & \pm 5 \\
\hline
\end{tabular}




\subsection{Panelists}

A total of 440 panelists participated in the olfactory tests (by 87 certified odor measurement agencies) for this study, as demonstrated in Table 2: 225 for the testing of the site boundary PTMs and 215 for the outlet PTMs. The number of PTM samples for the air dilution olfactory testing was 261: three for each certified odor measurement agency. Five panelists tested one sample, so 1,305 test results with different panelist characteristics were collected. To allow analysis of the influence of different panel member characteristics on the result of ADOM testing, four of the characteristics of each panelist (i.e., sex, age, how many participations in such tests, and whether they smoked or not) were written on the records of the olfactory tests. The panel that participated in the test included only people who had passed a panel screening test in advance.

Table 2. 225 for the Testing of the Site Boundary PTMs and 215 for the Outlet PTMs

\begin{tabular}{cccc}
\hline \multirow{2}{*}{ Panel classification } & \multicolumn{2}{c}{ N } \\
\cline { 3 - 4 } & & Site boundary & Odor outlets \\
\hline Certified odor measurement agencies & 43 & 45 \\
\hline \multirow{2}{*}{ Gender } & Male & 85 & 110 \\
\cline { 2 - 4 } & Female & 135 & 105 \\
\hline \multirow{2}{*}{ Age } & $20-29$ & 112 & 72 \\
& $30-39$ & 87 & 68 \\
Experience & $>40$ & 21 & 75 \\
frequency & $0-20$ & 85 & 63 \\
& $21-40$ & 46 & 35 \\
& $>100$ & 61 & 65 \\
Smoke & Smoker & 28 & 52 \\
& Non-smoker & 205 & 24 \\
\hline
\end{tabular}

\subsection{Air Dilution Olfactory Method}

Fig. 1 displays the process of the air dilution olfactory method test. Panelists who passed the panel screening test smell odorless air and the PTMs and then take a five-minute rest. The operator of the testing distributes one bag of the site boundary PTMs at 1/10 dilution and another of the outlet PTMs with $1 / 300$ dilution rate (initially diluted samples). These are diluted again to differ

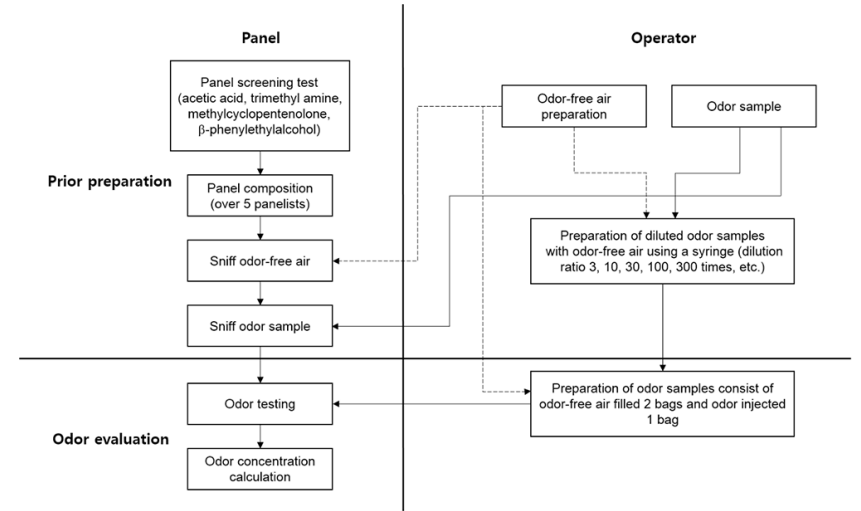

Fig. 1. The process of the air dilution olfactory method test.

ent concentrations. Two bags of odorless air are also provided to panelists. The panelists wear masks during a sensory test and push the sample bag and air bags with their hands, to smell them for two to three seconds. The operator calculates the rate of correct answers for all panelists. When the average rate of correct answers is $<0.6$, the operator stops the test. When a panelist picks the PTM bag, 1.00 point is given and when he picks the odorless air bag, 0.00 point is given for the calculation of the rate of correct answers. When the rate is 0.6 or higher after one round of testing, the PTM sample at the next level of dilution is tested by making panelists test one bag of PTMs and two bags of odorless air again. When less than one panelist gives the correct answer for the testing of the PTM sample of the next level of dilution rate, the test stops and the result is calculated. As shown in Table 3, the geometric mean of all the dilution rates, except for the maximum and minimum values, is regarded as the dilution rate of sensing for all panelists [5].

\subsection{Data Analysis}

In order to express the deviation of each panelist's sensing of odor from a central statistic, the ADOM test's $\mathrm{D} / \mathrm{T}$ (dilution to threshold) value (of which centralization is heightened by dismissing the maximum and minimum values) is first calculated. Then, the geometric mean between the ADOM test $\mathrm{D} / \mathrm{T}$ value, and the $\mathrm{D} / \mathrm{T}$ value of all panelists (five in one group), is set as the median value. Finally, the deviation between the median value and $\mathrm{D} / \mathrm{T}$ value of each panelist is calculated.

In the process, a one-notch increase in the dilution rate of PTMs (e.g., 1/100, 1/300, 1/1,000) is equivalent to a 0.5 increase

Table 3. Example of Air Dilution Olfactory Method on Outlets Odor Sample

\begin{tabular}{|c|c|c|c|c|c|c|c|c|}
\hline \multirow{2}{*}{ Panel } & \multicolumn{5}{|c|}{ Multiple of dilution } & \multirow{2}{*}{$\begin{array}{l}\text { Threshold value of } \\
\text { each panel }\end{array}$} & \multirow{2}{*}{$\begin{array}{l}\text { Exception of Max. } \\
\text { and Min. }\end{array}$} & \multirow{2}{*}{$\begin{array}{c}\text { Calculated dilution } \\
\text { factor }\end{array}$} \\
\hline & 100 & 300 & 1,000 & 3,000 & 10,000 & & & \\
\hline A & $\circ$ & $\mathrm{x}$ & & & & 100 & Exception & \multirow{5}{*}{$\begin{array}{c}\sqrt[3]{300 \times 300 \times 1000} \\
=448\end{array}$} \\
\hline $\mathrm{B}$ & o & ○ & $\mathrm{x}$ & \multirow{3}{*}{ ○ } & & 300 & & \\
\hline $\mathrm{C}$ & o & ○ & ० & & $\circ$ & 10,000 & Exception & \\
\hline $\mathrm{D}$ & $\circ$ & ० & $\mathrm{x}$ & & & 300 & & \\
\hline $\mathrm{E}$ & ० & ० & ० & $\mathrm{x}$ & & 1,000 & & \\
\hline
\end{tabular}


on the log scale. As the application of logarithms is appropriate for quantitatively interpreting human senses, the standard deviation was calculated by applying logarithms. Eq. (1) is the expression of the geometric mean of the dilution to threshold rates of all panelists who participated in the ADOM test and the log $\left(\frac{D}{T_{p i}}\right)$ deviation of each panelist, which was used to calculate the deviation in each panelist's sensing of odor from the mean.

$$
\operatorname{Dev}\left(\frac{D}{T_{\text {total }}}\right)_{p i}=\log \left(\frac{D}{T_{p i}}\right)-\log \left(\sqrt[n]{\frac{D}{T_{p 1}} \times \frac{D}{T_{p 2}} \times \cdots \times \frac{D}{T_{p n}}}\right)
$$

In the equation, $\operatorname{Dev}\left(\frac{D}{T_{\text {total }}}\right)$ is the log deviation between panelist i's $\mathrm{D} / \mathrm{T}$ value and the geometric mean of all panelists' $\mathrm{D} / \mathrm{T}$ values. Here, $\frac{D}{T_{p i}}$ is panelist i's $\mathrm{D} / \mathrm{T}$ and $\mathrm{n}$ is the number of panelists who participated in the air dilution olfactory test (five).

In addition, as the standard method of odor compounds of Korea uses the geometric mean of dilution rates excluding the maximum and minimum from all $\mathrm{D} / \mathrm{T}$ rates, the deviation of each panelist's sensing of odor was calculated by applying Eq. (2).

$$
\operatorname{Dev}\left(\frac{D}{T_{3}}\right)_{p i}=\log \left(\frac{D}{T_{p i}}\right)-\log \left(\sqrt[3]{\frac{\frac{D}{T_{p 1}} \times \frac{D}{T_{p 2}} \times \cdots \times \frac{D}{T_{p 5}}}{\frac{D}{T_{p M A X}} \times \frac{D}{T_{p M I N}}}}\right)
$$

In the equation, $\operatorname{Dev}\left(\frac{D}{T_{3}}\right)_{p i}$ is the log deviation of panelist i's $\mathrm{D} / \mathrm{T}$ from the geometric mean of $\mathrm{D} / \mathrm{T}$ values excluding the maximum and minimum, and is the maximum, and $\frac{D}{T_{p M A X}}$ is $\frac{D}{T_{p M I N}}$ the minimum, dilution rate.

\section{Results and Discussion}

\subsection{Result of Homogeneity and Stability Testing of Site Boundary and Outlet PTMs}

In order to assess the homogeneity between the site boundary and outlet PTM samples, three groups of panelists were selected. Each group engaged in three repeated air dilution olfactory tests for the site boundary and outlet PTMs. The result of the homogeneity and stability experiment on the site boundary and outlet PTMs is demonstrated in Fig. 2. In the homogeneity testing, the $\log$ value of the dilution rate for Group 1 was $1.761 \pm$ 0.102; for Group 2, $1.761 \pm 0.102$; and for Group 3, $1.820 \pm$ 0.000 for the site boundary PTMs. The dilution rate log value for the outlet PTMs was $3.709 \pm 0.101$ for Group 1; $3.709 \pm$ 0.101 for Group 2; and $3.477 \pm 0.000$ for Group 3. The result of the homogeneity test shows that there was no difference between the odor intensity of the site boundary and outlet PTM samples.
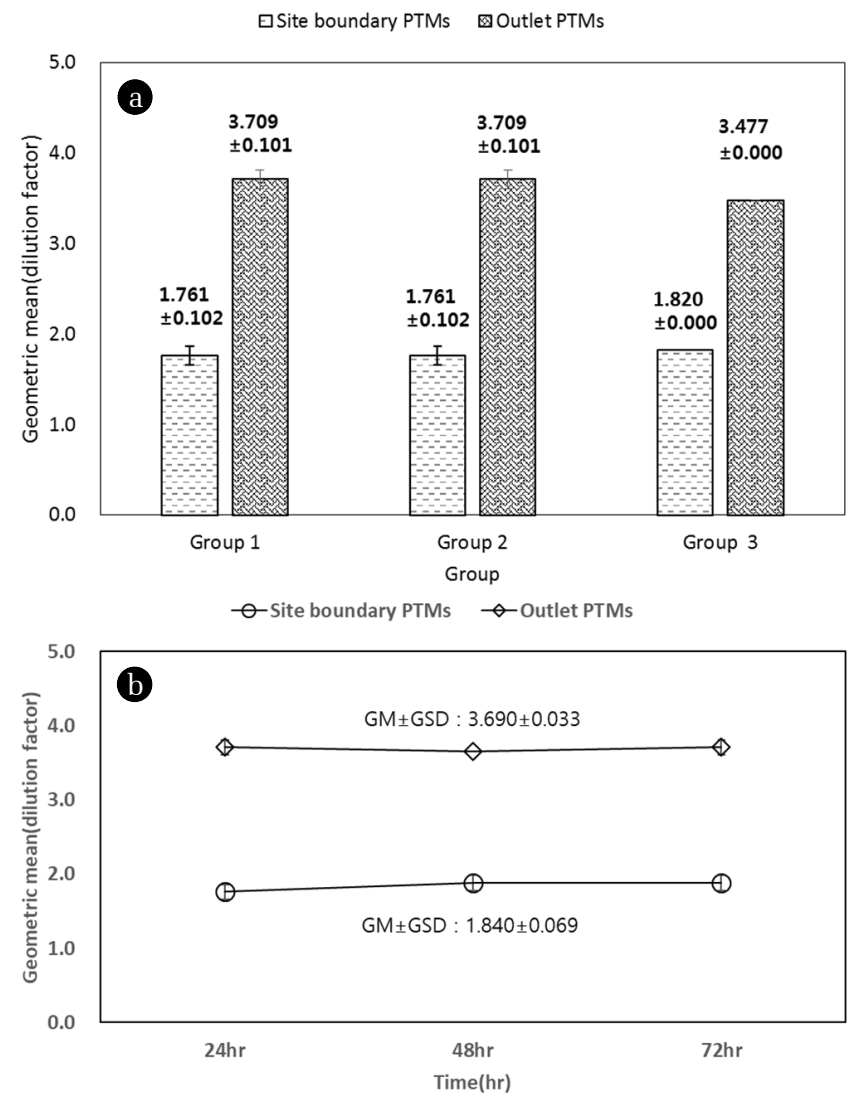

Fig. 2. (a) Homogeneity and (b) stability test results of site boundary and outlet PTMs.

In order to assess the stability of the site boundary and outlet PTM samples, one group of panelists engaged in three repeated air dilution olfactory tests for the site boundary and outlet PTMs, for three days. For the site boundary PTMs, the log value of the dilution rate for $72 \mathrm{~h}$ was $1.840 \pm 0.033$. The value was $3.690 \pm 0.033$ for the outlet PTMs. The deviation between the hourly $\log$ values of dilution rates was not significant, which indicates that the stability of the PTM samples was maintained over time [17].

\subsection{General Characteristics of $\operatorname{Dev}\left(D / T_{\text {total }}\right)$ and $\operatorname{Dev}\left(D / T_{3}\right)$}

The result of $\operatorname{Dev}\left(\mathrm{D} / \mathrm{T}_{\text {total }}\right)$ and $\operatorname{Dev}\left(\mathrm{D} / \mathrm{T}_{3}\right)$ is displayed in Table 4. The results for site boundary and outlet tests are marked separately. The mean value of $\operatorname{Dev}\left(\mathrm{D} / \mathrm{T}_{\text {total }}\right)$ for the value of all panelists is ' 0 '. As the mean value of the test results of all panelists was set as the median value for the calculation of the deviation, the sum becomes ' 0 '. The mean value of $\operatorname{Dev}\left(\mathrm{D} / \mathrm{T}_{3}\right)$ was -0.002 for the site boundary PTMs and 0.005 for the outlet PTMs. The outlet PTMs, which were more highly concentrated, showed values slightly higher than the total value. There was no difference for the site boundary PTMs with relatively low concentrations.

Before analysis of the results, the mean value of different $\operatorname{Dev}\left(\mathrm{D} / \mathrm{T}_{\text {total }}\right)$ dilution rates and $\operatorname{Dev}\left(\mathrm{D} / \mathrm{T}_{3}\right)$ values were displayed in Table 5. The ' + ' values indicate factors that are favorable for olfactory sensing when compared to the median value. Against 
Table 4. Mean and Standard Deviation of $\operatorname{Dev}\left(\mathrm{D} / \mathrm{T}_{\text {total }}\right) \& \operatorname{Dev}\left(\mathrm{D} / \mathrm{T}_{3}\right)$

\begin{tabular}{lcccccc}
\hline & Site & $\mathbf{n}$ & Mean & SD & Range \\
\hline \multirow{3}{*}{$\operatorname{Dev}\left(\mathrm{D} / \mathrm{T}_{\text {total }}\right)$} & Site boundary & 660 & 0.000 & 0.387 & $-1.083-1.440$ & $-0.828-1.172$ \\
& Outlet & 645 & 0.000 & 0.348 & $-1.946-2.054$ \\
\hline \multirow{3}{*}{$\operatorname{Dev}\left(\mathrm{D} / \mathrm{T}_{3}\right)$} & Overall & 1,305 & 0.000 & -0.047 & $-0.827-0.915$ \\
& Site boundary & 660 & 0.326 & 0.281 & $-0.823-0.700$ \\
& Outlet & 645 & 0.005 & 0.002 & $-1.686-1.579$ \\
\hline
\end{tabular}

Table 5. $\operatorname{Dev}\left(\mathrm{D} / \mathrm{T}_{\text {total }}\right) \& \operatorname{Dev}\left(\mathrm{D} / \mathrm{T}_{3}\right)$ Mean Value of Panel Characteristic and Range

\begin{tabular}{|c|c|c|c|c|}
\hline & \multicolumn{2}{|c|}{$\operatorname{Dev}\left(\mathrm{D} / \mathrm{T}_{\text {total }}\right)$} & \multicolumn{2}{|c|}{$\operatorname{Dev}\left(\mathrm{D} / \mathrm{T}_{3}\right)$} \\
\hline & Site boundary & Outlet & Site boundary & Outlet \\
\hline Male & 0.001 & -0.020 & 0.051 & -0.024 \\
\hline Female & 0.000 & 0.020 & -0.029 & 0.012 \\
\hline Smoker & 0.026 & -0.120 & 0.047 & -0.093 \\
\hline Non-smoker & -0.002 & 0.015 & -0.003 & 0.007 \\
\hline Age (20-29) & -0.013 & 0.059 & -0.011 & 0.045 \\
\hline Age (30 ) & 0.014 & -0.029 & 0.021 & -0.033 \\
\hline Experienced (0-30) & -0.003 & 0.013 & 0.000 & -0.009 \\
\hline Experienced (30 ) & 0.003 & -0.008 & 0.005 & -0.001 \\
\hline
\end{tabular}

the benchmark of ' 0 ', 0.05 is equivalent to approximately $12 \%$ deviation. For the site boundary PTMs, men aged 30 or older, smokers, and those who have participated in 30 or more air dilution olfactory tests showed favorable deviations. For the outlet PTMs, women aged 30 or younger, non-smokers, and those who have participated in 30 or less air dilution olfactory tests showed favorable deviations.

\subsection{Frequency Distribution of $\operatorname{Dev}\left(D / T_{\text {total }}\right)$ and $\operatorname{Dev}\left(D / T_{3}\right)$}

The frequency distribution of $\operatorname{Dev}\left(\mathrm{D} / \mathrm{T}_{\text {total }}\right)$ and $\operatorname{Dev}\left(\mathrm{D} / \mathrm{T}_{3}\right)$ is shown in Fig. 3, respectively. $\operatorname{Dev}\left(\mathrm{D} / \mathrm{T}_{\text {total }}\right)$ in Fig. 3(a) shows a distribution characteristic similar to a normal distribution. A deviation larger than \pm 0.5 is the interval where the deviation of the dilution rate is larger than one notch from the median value, while the interval where the deviation is larger than \pm 1.0 is the interval where the dilution rate deviation is larger than two notches from the median value. There was no frequency where the result of each panelist's sensing and his group's sensing was the same. In the frequency of the interval where the dilution rate deviation was within one-notch difference (between -0.5 and 0.5 ), the level of centralization was approximately $83.2 \%$ ( $n=1,086$ ) of the entire interval. The frequency of exceeding the \pm 1.0 dilution rate deviation was $0.5 \%(\mathrm{n}=6)$.

The frequency distribution of $\operatorname{Dev}\left(\mathrm{D} / \mathrm{T}_{3}\right)$ in Fig. 4(b) shows that there was no frequency interval where the result of each panelist's sensing and the result of sensing by three panelists (except for the maximum and minimum) were the same. The frequency of the interval of less than one-notch deviation (between -0.5 and 0.5$)$ took up 90.8\% $(\mathrm{n}=711)$ of the entire interval and there was no frequency for dilution rate deviation $> \pm 1.0$.
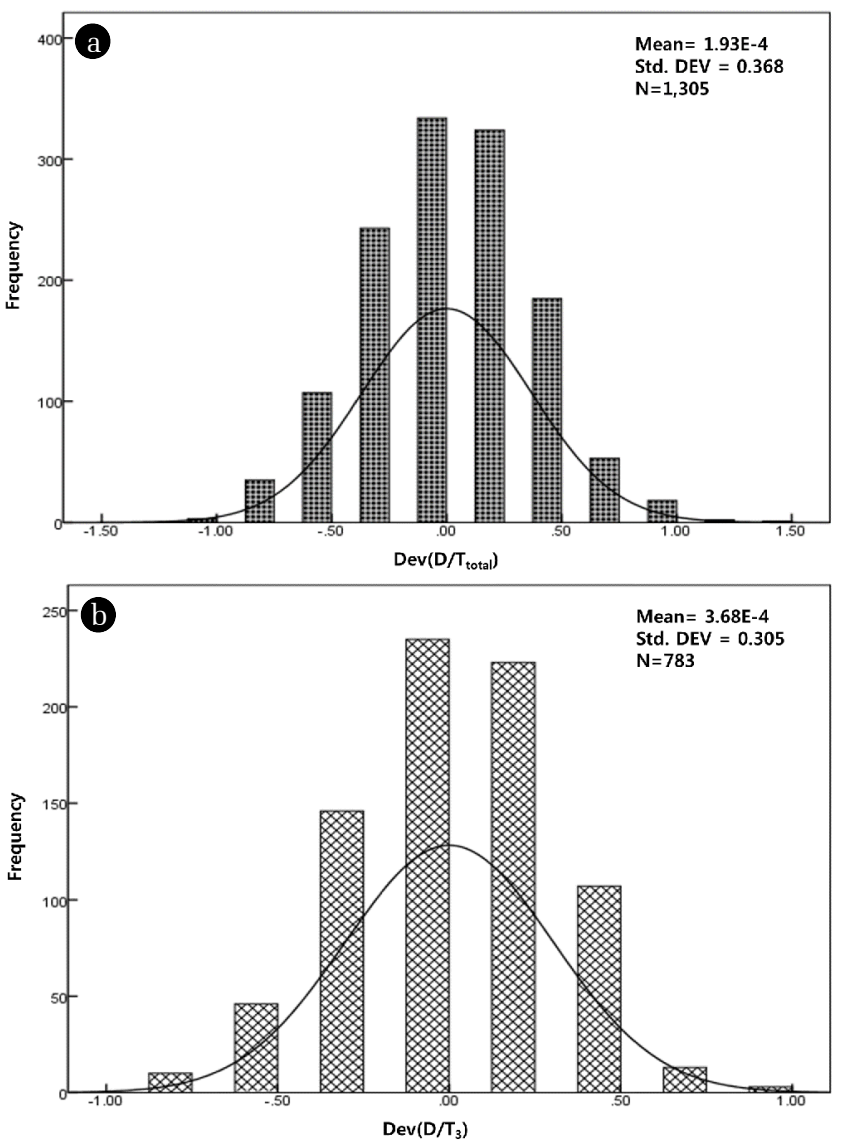

Fig. 3. Frequency distribution of (a) $\operatorname{Dev}\left(\mathrm{D} / \mathrm{T}_{\text {total }}\right)$ site boundary and outlet and (b) $\operatorname{Dev}\left(\mathrm{D} / \mathrm{T}_{3}\right)$ site boundary and outlet. 
In summary, the $\operatorname{Dev}\left(\mathrm{D} / \mathrm{T}_{\text {total }}\right)$ distribution showed a generally even form and the level of centralization was high in the frequency where the dilution rate deviation was within one-notch difference. On the contrary, for the frequency distribution of $\operatorname{Dev}\left(\mathrm{D} / \mathrm{T}_{3}\right)$, the frequency around the median value was substantially higher, so the effect of the dismissal of the maximum and minimum values appears to be crucial.

In conclusion, $\operatorname{Dev}\left(\mathrm{D} / \mathrm{T}_{\text {total }}\right)$ shows a form similar to the form of a normal distribution, thus it is thought to be more appropriate for the assessment of influence from the panel. Plus, because $\operatorname{Dev}\left(\mathrm{D} / \mathrm{T}_{3}\right)$ is based on the current official testing method implemented in Korea, a concurrent assessment is necessary for the identification of the effect that the influence from the panel can have on administrative dispositions.

\subsection{Influence of Panel Characteristics on the Result of Olfactory Test}

People on the panel of an ADOM test have a variety of different characteristics including such as their sex, age, smoking status, and number of olfactory tests they have participated in; so, the effect of those complex factors on the test results should be considered. Therefore, such effect was analyzed by comparing the median value of each characteristic factor of panelists. As shown in Fig. 4, site boundary $\operatorname{Dev}\left(\mathrm{D} / \mathrm{T}_{\text {total }}\right)$ and $\operatorname{Dev}\left(\mathrm{D} / \mathrm{T}_{3}\right)$ were higher from the median value for men than for women. The figures were also higher from the median value for smokers than for non-smokers. By age group, the figures were higher from the median value for people who were aged 30 or older than for those aged under 30. The figures were also higher from the median value for people who had participated in 30 or more air dilution olfactory tests than for those who had participated in $<30$ such tests. Such results are thought to be attributable to the difficulty in clearly identifying the effect of panelist characteristics factors on the test result, due to the low concentrations of the site boundary PTMs.
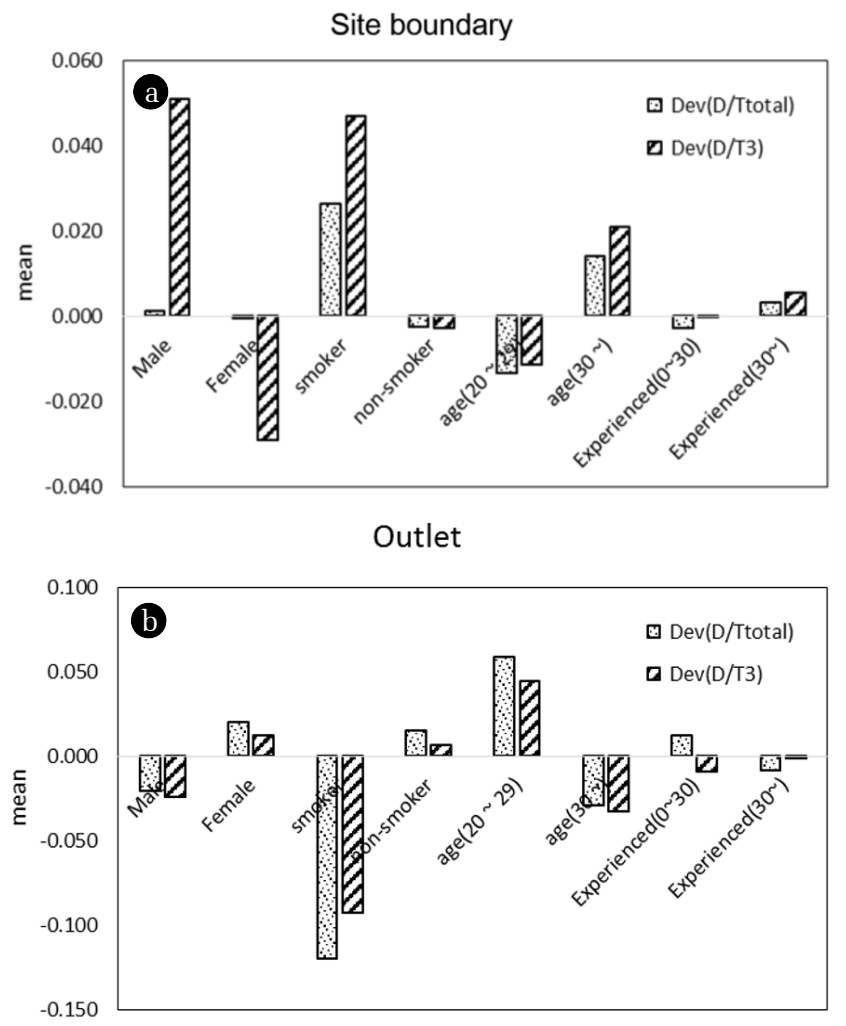

Fig. 4. (a) $\operatorname{Dev}\left(D / T_{\text {total }}\right)$ mean values and (b) $\operatorname{Dev}\left(D / T_{3}\right)$ mean values of multi character panel group.

Table 6. Dilution to Threshold $T_{\text {total }}$ and $T_{3}$ p-value of Characteristic and Range

\begin{tabular}{|c|c|c|c|c|c|c|c|c|c|c|}
\hline & Site & Division & Male & Female & Smoker & Non-smoker & $\begin{array}{c}\text { Age } \\
(20-29)\end{array}$ & $\begin{array}{l}\text { Age } \\
(30 \sim)\end{array}$ & $\begin{array}{c}\text { Experienced } \\
(0-30)\end{array}$ & $\begin{array}{c}\text { Experienced } \\
(30 \sim)\end{array}$ \\
\hline \multirow{6}{*}{$\begin{array}{c}\text { Dilution to } \\
\text { threshold } \\
\mathrm{T}_{\text {total }}\end{array}$} & \multirow{3}{*}{ Boundary } & $\mathrm{N}$ & 262 & 398 & 60 & 600 & 335 & 325 & 338 & 322 \\
\hline & & $\mathrm{p}$-value & \multicolumn{2}{|c|}{0.960} & \multicolumn{2}{|c|}{0.584} & \multicolumn{2}{|c|}{0.360} & \multicolumn{2}{|c|}{0.842} \\
\hline & & $\begin{array}{l}\text { Log (dilution to } \\
\text { threshold) mean }\end{array}$ & 1.561 & 1.560 & 1.586 & 1.558 & 1.547 & 1.574 & 1.557 & 1.563 \\
\hline & \multirow{3}{*}{ Outlet } & $\mathrm{n}$ & 317 & 328 & 72 & 573 & 215 & 430 & 264 & 381 \\
\hline & & $\mathrm{p}$-value & \multicolumn{2}{|c|}{0.136} & \multicolumn{2}{|c|}{0.002} & \multicolumn{2}{|c|}{0.003} & \multicolumn{2}{|c|}{0.458} \\
\hline & & $\begin{array}{l}\text { Log (dilution to } \\
\text { threshold) mean }\end{array}$ & 3.285 & 3.325 & 3.185 & 3.320 & 3.364 & 3.276 & 3.318 & 3.297 \\
\hline \multirow{6}{*}{$\begin{array}{c}\text { Dilution to } \\
\text { threshold } \\
\mathrm{T}_{3}\end{array}$} & \multirow{3}{*}{ Boundary } & $\mathrm{n}$ & 156 & 240 & 41 & 355 & 228 & 168 & 212 & 184 \\
\hline & & p-value & \multicolumn{2}{|c|}{0.017} & \multicolumn{2}{|c|}{0.358} & \multicolumn{2}{|c|}{0.331} & \multicolumn{2}{|c|}{0.864} \\
\hline & & $\begin{array}{l}\text { Log (dilution to } \\
\text { threshold) mean }\end{array}$ & 1.611 & 1.531 & 1.607 & 1.557 & 1.549 & 1.581 & 1.560 & 1.565 \\
\hline & \multirow{3}{*}{ Outlet } & $\mathrm{n}$ & 182 & 205 & 45 & 342 & 140 & 247 & 167 & 220 \\
\hline & & $\mathrm{p}$-value & \multicolumn{2}{|c|}{0.207} & \multicolumn{2}{|c|}{0.025} & \multicolumn{2}{|c|}{0.009} & \multicolumn{2}{|c|}{0.784} \\
\hline & & $\begin{array}{l}\text { Log (dilution to } \\
\text { threshold) mean }\end{array}$ & 3.281 & 3.317 & 3.212 & 3.312 & 3.350 & 3.272 & 3.296 & 3.304 \\
\hline
\end{tabular}


As for the outlet PTMs, $\operatorname{Dev}\left(\mathrm{D} / \mathrm{T}_{\text {total }}\right)$ and $\operatorname{Dev}\left(\mathrm{D} / \mathrm{T}_{3}\right)$ were higher from the median value for women than for men, and for non-smokers than for smokers. The figures showed the same trend for people aged 29 or under, than for those who aged over 30. This was also true for people who had participated in ADOM tests less than 30 times than for those who had done tests 30 times or more.

The result of the analysis on the distribution among all panelists is demonstrated in Table 6. If the p-value is $<0.05$ (significance level of 5\%) in the result of analysis of variance, the null hypothesis that the level of variance of the values is the same, is rejected. This means, in conclusion, that the values are significantly different. As demonstrated by the result of $\operatorname{Dev}\left(\mathrm{D} / \mathrm{T}_{\text {total }}\right)$ panel, it was difficult to identify differences in the result according to panelists' sex, age, smoking status, and number of air dilution olfactory tests in which they had participated, for the site boundary PTMs. As for the outlet PTMs, the p-value for the smoking status and age was 0.002 and 0.003 , respectively, which indicates that there were distinct differences between two groups: between smokers and non-smokers, and between people aged over 30 and aged 29 or younger.

In the $\operatorname{Dev}\left(\mathrm{D} / \mathrm{T}_{3}\right)$ result excluding the maximum and minimum in Table 6, the p-value of sex for the site boundary PTMs was 0.017, which indicates that there was a difference between men and women. Differences according to age, smoking status, and past experience of olfactory testing were not identified. For the outlet PTMs, the p-value for smoking status and age was 0.025 and 0.009 , respectively, indicating that there were distinct differences between two groups: between smokers and non-smokers, and between people aged over 30 and aged 29 or younger.

\section{Conclusions}

In this study, when the characteristics of panelists who participated in air dilution olfactory testing (e.g., sex, age, smoking status, and number of participations in olfactory tests) were analyzed, men, smokers, people aged 30 or older, and those who had participated in 30 or more olfactory tests showed favorable deviations for the site boundary PTMs; while women, non-smokers, people aged under 30, and those who had participated in less than 30 olfactory tests showed favorable deviations for the outlet PTMs.

In sensitivity to n-butanol, although male panelists surpassed female panelists, it was not statistically significant. Olfactory sensitivity to environmental odor was decreased with age [18]. However, women were inclined to score batter than men at almost all age groups on standardized tests of odor identification and odor detection on odor-stimulated functional magnetic resonance imaging [19]. The regional environment effect, such as air pollution, is an important factor in the deterioration of the olfactory acuity [11].

When differences in the results of olfactory testing were reviewed in relation to characteristics of the panelists, the result of entire panels for the site boundary PTMs showed no difference according to panelist sex, age, smoking status, and past partic- ipation in ADOM tests. As for the outlet PTMs, distinct differences appeared in relation to the smoking status and age of panelists. However, it is possible that many factors, such as natural environmental conditions, cultures, and life-long experience, may also influence on olfactory ability. Then, the real effects of various factors that are capable of affecting the sense of smell should be evaluated from a variety of approaches to take into account their validity, importance, and function in the daily environment of panelists. Also, further research would be obviously needed for the correlation analysis between various panelist characteristics factors (i.e., age and smoking status).

\section{Acknowledgments}

This research was supported by the Daejeon University fund in 2015

\section{References}

1. Curren J. Characterization of odor nuisance. California: Univ. of California; 2012.

2. Gebicki J. Application of electrochemical sensors and sensor matrixes for measurement of odorous chemical compounds. TrAC Trends Anal. Chem. 2016;77:1-13.

3. Muñoz R, Sivret EC, Parcsi G, et al. Monitoring techniques for odour abatement assessment. Water Res. 2010;44:5129-5149.

4. Wilson $\mathrm{AD}$, Baietto M. Applications and advances in electronic-nose technologies. Sensors 2009;9:5099-5148.

5. Ministry of Environment. Odor analysis method in South Korea. Korea's Ministry of Environment; 2014.

6. Kim JB, Jeong SJ. The relationship between odor unit and odorous compounds in control areas using multiple regression analysis. J. Environ. Health Sci. 2009;35:191-200.

7. Kim JB, Jeong SJ, Song IS. The concentrations of sulfur compounds and sensation of odor in the residential area around Banwol-Sihwa industrial complex. J. Korean Soc. Atmos. Environ. 2007;23:147-157.

8. Gebicki J, Byliński H, Namieśnik J. Measurement techniques for assessing the olfactory impact of municipal sewage treatment plants. Environ. Monit. Assess. 2016;188:1-15.

9. Kaneda H, Maeshima K, Goto N, Kobayakawa T, Kanamura $\mathrm{S}$, Saito S. Decline in taste and odor discrimination abilities with age, and relationship between gustation and olfaction. Chem. Senses 2000;25:331-337.

10. Barkat S, Le Berre E, Coureaud G, Sicard G, Thomas-Danguin T. Perceptual blending in odor mixtures depends on the nature of odorants and human olfactory expertise. Chem. Senses 2012;37:159-166.

11. Sorokowska A, Sorokowski P, Frackowiak T. Determinants of human olfactory performance: A cross-cultural study. Sci. Total Environ. 2015;506-507:196-200.

12. Sulmont-Rossé C, Maître I, Amand M, et al. Evidence for different patterns of chemosensory alterations in the elderly population: Impact of age versus dependency. Chem. Senses 2015;40:153-164. 
13. European committee for standardization. CSN EN 13725 Air quality - Determination of odour concentration by dynamic olfactometry; 2003.

14. Kim ST, Lee SJ, Hong SY, et al. The study on VOCs PTMs (Proficiency Testing Materials) as a complex malodor sampler for air dilution olfactory method. J. Korean Soc. Odor Res. Eng. 2013;12:59-68.

15. ISO 6142. Gas analysis - Preparation of calibration gas mixtures - Gravimetric method. 2001.

16. ISO 6143. Gas analysis - Comparison methods for determining and checking the composition of calibration gas mixtures. 2001.
17. Lee SJ, Yim B, Cho SJ, Choi SH, Kim MO, Kim ST. Analysis of error cases induced with regard to the calculation of the dilution factor during the proficiency test of certified odor measurement agencies. J. Odor Indoor Environ. 2014;13: 290-296.

18. Bliss PJ, Schulz TJ, Senger T, Kaye RB. Odour measurement - Factors affecting olfactometry panel performance. Water Sci. Technol. 1996;34:549-556.

19. Yousem DM, Maldjian JA, Siddiqu F, et al. Gender effects on odor-stimulated functional magnetic resonance imaging. Brain Res. 1999;818:480-487. 